\title{
Applying Principles of Uncertainty within Coastal Hazard Assessments to Better Support Coastal Adaptation
}

\author{
Scott A. Stephens ${ }^{1, *}$ (D) , Robert G. Bell ${ }^{1}$ and Judy Lawrence ${ }^{2}$ \\ 1 National Institute of Water and Atmospheric Research, Hamilton 3251, New Zealand; rob.bell@niwa.co.nz \\ 2 New Zealand Climate Change Research Institute, Victoria University of Wellington, Wellington 6140, \\ New Zealand; judy.lawrence.@vuw.ac.nz \\ * Correspondence: scott.stephens@niwa.co.nz; Tel.: +64-7-856-7026
}

Received: 30 May 2017; Accepted: 24 August 2017; Published: 29 August 2017

\begin{abstract}
Coastal hazards result from erosion of the shore, or flooding of low-elevation land when storm surges combine with high tides and/or large waves. Future sea-level rise will greatly increase the frequency and depth of coastal flooding and will exacerbate erosion and raise groundwater levels, forcing vulnerable communities to adapt. Communities, local councils and infrastructure operators will need to decide when and how to adapt. The process of decision making using adaptive pathways approaches, is now being applied internationally to plan for adaptation over time by anticipating tipping points in the future when planning objectives are no longer being met. This process requires risk and uncertainty considerations to be transparent in the scenarios used in adaptive planning. We outline a framework for uncertainty identification and management within coastal hazard assessments. The framework provides a logical flow from the land use situation, to the related level of uncertainty as determined by the situation, to which hazard scenarios to model, to the complexity level of hazard modeling required, and to the possible decision type. Traditionally, coastal flood hazard maps show inundated areas only. We present enhanced maps of flooding depth and frequency which clearly show the degree of hazard exposure, where that exposure occurs, and how the exposure changes with sea-level rise, to better inform adaptive planning processes. The new uncertainty framework and mapping techniques can better inform identification of trigger points for adaptation pathways planning and their expected time range, compared to traditional coastal flooding hazard assessments.
\end{abstract}

Keywords: sea-level rise; coastal hazard assessment; uncertainty; coastal adaptation; climate change

\section{Introduction}

Coastal hazards are physical phenomena that expose a coastal area to risk of property damage, loss of life and environmental degradation [1]. Coastal hazards include flooding during high storm-tides, large waves or tsunami, as well as the more gradual hazards of coastal erosion, high-tide inundation and rising groundwater levels, due to sea-level rise (SLR). Coastal hazards are an increasing problem. Sea level has been relatively stable during the last 2000-3000 years [2]. Civilization has developed near the upper limits of the sea's reach on the premise of a relatively "stable" sea level [3,4]. Global sea level began to rise in the late 1800s, due mainly to anthropogenic greenhouse gas emissions [5,6]. Anthropogenic SLR over this century and beyond will cause more frequent flooding of coastal land and saltwater intrusion into groundwater, geomorphological adjustment of the coastline, rising groundwater levels and vegetation change, e.g., [7]. With a SLR of $\sim 0.2 \mathrm{~m}$ since 1900, in low-lying areas of New Zealand there is an increased incidence of coastal storm flooding [8,9]. In the USA, SLR is causing deeper floods during extreme sea-level events, and more regular "nuisance" 
flooding during high tides, resulting in millions of dollars of insurance claims [10]. The rate of SLR is projected to accelerate over this century and beyond [3-5], which will greatly increase the frequency of flooding, e.g., [9-12], and exacerbate coastal erosion, e.g., [13] forcing communities to adapt in some way. Communities will need to decide when and how to adapt. For example, "adaptation tipping points" $[14,15]$ might be set to when the 1 in 100-year event becomes a 1 in 5 -year event, or when the 1 in 5-year event occurs several times per year, erosion reaches a pre-determined distance from houses, or to some measure of community coping capacity.

Government policies generally recognize the need to curtail rising coastal hazard risks over short to long timescales arising from SLR. The 2010 New Zealand Coastal Policy Statement (NZCPS), which has statutory power, requires the identification of areas in the coastal environment that are "potentially affected" by coastal hazards, and assessment of the associated risks over at least the next 100 years (Policy 24). The NZCPS requires a risk-based approach to managing coastal hazards (Policies 24-25 and 27)—which requires determination of the likelihoods of different magnitude events and their consequences, i.e., risk $=$ likelihood $\times$ consequence. However, likelihood can be difficult to assign over the long-term due to uncertainties, yet consequences could be high. The uncertainty framework presented in this paper was motivated by a need to guide local government in New Zealand, when commissioning coastal hazard assessments (to give effect to the NZCPS policies) for input to the dynamic adaptive policy pathways (DAPP) process [16]. The framework and concepts were developed while revising the coastal hazards and climate change guidance manual for local government in New Zealand [17]. The revision is due for final release in late 2017.

The purpose of a coastal hazard assessment is to provide the exposure information for risk and vulnerability assessments necessary for decision making, including the uncertainties, in a way that is clearly understood. Such assessments must identify the spatial extent and magnitude of hazard exposure, both now and with future higher sea level, and must quantify the likelihood of occurrence of the hazards, recognizing the uncertainties in the future by distinguishing under what conditions probabilistic approaches are appropriate or where scenarios supported by expert judgement are more appropriate. The hazard and uncertainty information is required by planners, asset managers and decision makers, and for input to engagement processes with potentially affected communities (property owners and residents) and wider stakeholders.

When considering the ongoing, but increasing effects of climate change on coastal hazards, uncertainty is fundamental to how the problem is addressed. For coastal areas, it is "virtually certain" that SLR will continue beyond 2100 for many centuries [5] — but what is deeply uncertain is the rate of rise in sea level and magnitudes at junctures over long timeframes $[5,6,18]$. This uncertainty results in a wide future window within which further substantial exposure could occur. There is more certainty in the near-term for adaptation decisions, e.g., global SLR by 2040-2060 is projected to be in a relatively narrow likely range of $0.16-0.33 \mathrm{~m}$ (above 1986-2005 base) across all emission scenarios, compared with the range at 2100 and beyond $[5,18,19]$. This means that near-term decisions need to build in flexibility, both to reduce exposure and to enable changes to actions, or pathways that can accommodate higher sea levels over longer timeframes. Such actions should integrate the decision life-time, so as not to lock in path dependency arising from the inflexibility of the decision made now $[16,19,20]$.

The clear identification and separation of uncertainty sources is important in any coastal hazard assessment, because confusion could lead to false representation of true uncertainty, resulting in sub-optimal adaptation planning and decision making. Walker et al. [21] introduced an uncertainty framework aimed at providing a conceptual basis for the systematic treatment of uncertainty in model-based decision support, such as the coastal hazard assessment considered here. In Section 3 we briefly review this framework and recent revisions [22,23], and apply it to coastal hazard assessment considering SLR and coastal storm flooding likelihood.

Assessment and adaptation approaches that explicitly deal with uncertainty and the changing character of risk need to be used in coastal areas to avoid inflexible and path-dependent decisions. Such approaches can assess the consequences component of risk, but likelihood of potentially-large future 
SLR and climate change impacts is highly uncertain over longer timeframes. The DAPP process is a method for planning under conditions of uncertainty [16]; Haasnoot et al. [16] set out the basis of DAPP, review the literature leading to its development and provide examples of its application. DAPP integrates two existing adaptive planning approaches, Adaptive Policymaking $[24,25]$ and Adaptation Pathways [26]. Adaptive Policymaking provides a stepwise approach for developing a basic plan or policy, and contingency planning to adapt the plan or policy to new information over time. Adaptation Pathways provide insight into the sequencing of actions over time, potential lock-ins (i.e., a path taken now may lock in future negative consequences), and path dependencies [16]. Adaptation Pathways uses the concept of "adaptation tipping point" [27], which is the point at which a particular action is no longer adequate for meeting the agreed objectives and a new action is therefore necessary [16]. The exact timing of a tipping point is not necessary; but bracketing the time period should provide a clear indication-for example, "on average the tipping point will be reached within 50 years, at earliest within 40 years, and at latest within 60 years" [16]. Adaptive Policymaking uses "trigger points", which specify the conditions under which a pre-specified action to change the plan, is to be taken [16]. The combination of Adaptive Policymaking and Adaptation Pathways, DAPP, results from using the strengths of both approaches. This integrated approach includes: transient scenarios representing a variety of relevant uncertainties and their development over time; different types of actions to handle vulnerabilities and opportunities; Adaptation Pathways describing sequences of promising actions; and a monitoring system with related contingency actions to keep the plan on track with the objectives [16]. The basis of the DAPP process is that, given uncertainty about the future, one needs to design dynamic adaptive plans that allow future decisions to be changed in the light of new information (e.g., extensive monitoring of the impacts, changes in frequency of events and drivers such as SLR), with inherent flexibility to change course once certain trigger points are signaled. The change in course (to another pathway) may be delayed if slower than anticipated SLR occurs and the trigger point takes longer to reach, and conversely, an earlier change may be implemented if SLR is more rapid than expected, or if progress on reducing global emissions is limited. The DAPP process is now being used internationally to plan for adaptation to rising risk over time to anticipate tipping points for future decisions, irrespective of how the timing of climate change impacts unfolds, e.g., $[14,19,28]$.

In a coastal context, the DAPP process focuses on coastal hazard risks, particularly the consequences, and developing alternate pathways, and trigger points (with approximate bracketed time windows). It encompasses "testing" responses to climate change against a wide range of future (SLR/hazard) scenarios, which are used to develop dynamic adaptive policy pathways. Subsequent evaluation of these pathways can assess the accrued benefits, or otherwise, over their useful life, covering a range of possible timing for the trigger point being reached, Within the DAPP, coastal hazard assessments can be used to identify vulnerabilities and thresholds of intolerable or "nuisance" risk, to design adaptive policy pathways, and to identify triggers (decision points) for when to switch pathways before the threshold (tipping point) is reached (i.e., anticipatory rather than reactive) and objectives are no longer being met [16]. This enables adaptation to occur before thresholds are reached.

Since coastal hazard assessments take considerable time and resources, one difficulty faced by local government is knowing what hazard scenarios to model to provide an appropriate range of information to support the DAPP process. The 'uncertainty framework for coastal hazard assessment' outlined in Section 4, provides more targeted guidance on the scenarios to model that are tuned to the situation faced, the planning timeframe, and the appropriate management of the uncertainty. This meets the requirements of the DAPP process to examine the consequence, through testing scenarios, of situation-dependent SLR and storm-tide (or erosion) hazards. For example, the framework considers that a wide range of SLR scenarios is necessary when adapting to existing development (leaving aside low-risk assets for non-habitable use), and focuses on higher SLR scenarios over long timeframes if the aim is to avoid hazard risk when undertaking significant new development or change in land use. 
The goals of this paper are to: (i) reveal the multiple levels of uncertainty associated with SLR within the context of a formal uncertainty framework; (ii) show how an uncertainty framework might be applied to guide local government when commissioning coastal hazard assessment studies, to ensure that uncertainty is appropriately and transparently accounted for and the assessments provide information appropriate to the decision-making process within the DAPP; and (iii) demonstrate enhancements of coastal flood exposure mapping, which are tailored for adaptive decision making compared with conventional maps showing only the horizontal flooding extent. By isolating both flooding depth and frequency, such maps can clearly show the degree of hazard exposure and likelihood, where that hazard occurs (presently or emergent), and how the hazard exposure changes with SLR. These maps enable more informed community engagement and decision making around tolerability of risks.

The paper is organized as follows. In Section 2 we present SLR scenarios developed during revision of the New Zealand coastal hazard and climate change guidance, focusing on the earliest and latest arrival times for several SLR increments, to support the DAPP and hazard assessment processes. In Section 3 we review the conceptual basis for the systematic treatment of uncertainty and we apply it to consider the levels of uncertainty present within a coastal hazard assessment. In Section 4 we outline the 'uncertainty framework for coastal hazard assessment'. In Section 5 we provide a case study to demonstrate enhancements of coastal flood hazard mapping, and discuss the utility of the maps for the DAPP process. In Section 6 we provide a hypothetical example demonstrating the integration of all the preceding steps within the DAPP. Conclusions are given in Section 7.

\section{Sea-Level Rise Scenarios}

Changes in the rate of SLR depend on future greenhouse gas emissions [5]. The Intergovernmental Panel on Climate Change (IPCC) presented four greenhouse gas representative concentration pathways (RCP) in their Fifth Assessment Report, based on global climate modeling [5]. For each RCP, probability distributions have been developed that describe the statistical uncertainty of future SLR for the unique RCP scenario, but the scenarios cannot be assigned a specific likelihood [18,29]. The SLR scenarios for different RCPs are in relatively close agreement over the next few decades, but substantially diverge beyond about the year 2080 (Table 1). Furthermore, within each RCP, the SLR uncertainty widens considerably with time. The IPCC provided detailed SLR projections out to 2100, and only indicative projections beyond 2100, because of major uncertainty in the upper plausible range of SLR, due to the unknown future dynamical response of the polar ice sheets to warming and other potentially-unknown feedback mechanisms [5]. Therefore, a challenge for coastal hazard assessments is to account for the different types of uncertainty associated with SLR, such as statistical, scenario, and deep uncertainty [30]. These uncertainty terms are defined in Section 3.

Table 1 provides four SLR scenarios out to the year 2150, which are based around three greenhouse gas representative concentration pathways (RCP2.6, RCP4.5 and RCP8.5). Three of the scenarios are derived from the median projections of global SLR for three of the four RCPs presented by IPCC in their Fifth Assessment Report out to 2100 [5] and extended to 2150 by applying the rate of rise from the global projections of Kopp et al. [18]. The fourth ' $\mathrm{H}^{+\prime}$ scenario is at the upper-end of the "likely range" (i.e., 83rd-percentile) of the large ensemble of SLR projections based on RCP8.5 [18]. In particular, this higher scenario reflects the possibility of future surprises (deep uncertainty, Section 3) towards the upper range in SLR projections of an RCP8.5 scenario (recognizing that higher rises cannot be ruled out as shown by higher percentiles in Kopp et al. [18]). These more rapid rates of SLR could occur in the later part of this century and beyond, primarily from emerging polar ice sheet instabilities or as-yet uncertain understanding of dynamic ice sheet processes [18,31,32]. Note: All SLR scenarios in Table 1 have had a small offset of up to $0.05 \mathrm{~m}$ by 2100 (pro-rated to 2150) applied to account for slightly higher SLR projections in the regional sea around New Zealand compared to the global mean [33].

The four scenarios were used to develop bracketed timeframes to reach a specific increment of SLR, from the earliest to latest time across the RCP2.6, RCP4.5, RCP8.5 and $H^{+}$scenarios (Table 1). 
These timeframes can assist with the timing of triggers (decision points) in the DAPP process. They can be used where particular SLR triggers or associated thresholds for changes in frequency of flooding events have been established, based on vulnerability and risk assessments.

Table 1. Approximate years, from possible earliest to latest, when specific sea-level rise increments (meters above 1986-2005 baseline) could be reached for various projection scenarios of sea-level rise (SLR) for the wider New Zealand region. The earliest year listed is based on the representative concentration pathway RCP8.5 (83rd percentile) or $\mathrm{H}^{+}$projection and the next three columns are based on the median projections of the RCP8.5, 4.5 and 2.6 scenarios.

\begin{tabular}{ccccc}
\hline SLR $(\mathbf{m})$ & RCP8.5 $\mathbf{H}^{+}$(83rd Percentile) & RCP8.5 (Median) & RCP4.5 (Median) & RCP2.6 (Median) \\
\hline 0.3 & 2045 & 2050 & 2060 & 2070 \\
0.4 & 2055 & 2065 & 2075 & 2090 \\
0.5 & 2060 & 2075 & 2090 & 2110 \\
0.6 & 2070 & 2085 & 2110 & 2130 \\
0.7 & 2075 & 2090 & 2125 & 2155 \\
0.8 & 2085 & 2100 & 2140 & 2175 \\
0.9 & 2090 & 2110 & 2155 & 2200 \\
1.0 & 2100 & 2115 & 2170 & $>2200$ \\
1.2 & 2110 & 2130 & 2200 & $>2200$ \\
1.5 & 2130 & 2160 & $>2200$ & $>2200$ \\
1.8 & 2145 & 2180 & $>2200$ & $>2200$ \\
1.9 & 2150 & 2195 & $>2200$ & $>2200$ \\
\hline
\end{tabular}

\section{How Certain are We? Uncertainty is Important}

The clear identification and separation of uncertainty sources is important for coastal hazard assessment. Walker et al. [21] developed an uncertainty matrix as a framework for identifying and characterizing the uncertainty in model-based decision support. This framework has been adapted and modified in several studies, and was revised by Kwakkel et al. [22], and again by Walker et al. [23]. The framework suggests that uncertainty is a three-dimensional concept defined by: the location in the analysis, the level and the nature of the uncertainty. The location of the uncertainty could be in the conceptual model, the computer model, the input data, model implementation, or processed output data. The level denotes the degree or severity of the uncertainty, ranging from deterministic knowledge to total ignorance. The nature of the uncertainty arises from our lack of knowledge about the phenomena or to the inherent variability in the phenomena, or, to ambiguity because the same data can be interpreted differently by different persons depending on differences in frames and values. The nature of the uncertainty matters in choosing a strategy for handling uncertainty, because if the uncertainty is inherent variability, then more research will not help [22].

We focus here on how the different levels of uncertainty can be treated within a coastal hazard assessment, where the risk is rising with ever-widening spread of plausible SLR projections. A coastal hazard assessment can combine different sources of flooding, and because these sources have different levels of uncertainty, the uncertainty levels can be confused. For example, confusion of statistical and scenario uncertainty could give a misleading assurance of the true likelihood of outcomes and thus misinform decision making. Horton et al. [34] combine the probability distribution functions (pdf) of RCP4.5 and RCP8.5 SLR projections, assuming a 50\% likelihood for each to produce a single pdf for SLR, which they then combine with storm-tide distribution. The study provides statistical confidence of extreme sea levels being reached, but the combined distribution provides a false assurance, because the true likelihood of SLR scenarios used is largely unknown (within a wide range of possible futures beyond 2100 and uncertainty around how quickly global carbon emissions can be curbed). One might argue that this approach represents an expert ranking of the RCP scenarios, but our concern is that the RCP ranking then becomes conflated in the analysis and the implications are not able to be explored within a subsequent decision-making process. Focusing on only a single RCP scenario is 
another example where levels of uncertainty are not fully addressed. Several recent coastal erosion and flooding studies in New Zealand have calculated the statistical probability of future flooding and erosion hazards following $[35,36]$, but, possibly due to the computational expense, have only considered SLR projections associated with the continued high-emissions RCP8.5 median scenario, e.g., [37,38], rather than exploring sensitivity to other higher and lower scenarios. The resulting hazard maps consider only the statistics within the RCP8.5 scenario, and the possibility that the hazards could be quite different under another scenario is not available for consideration within a DAPP process. This becomes extremely contested in communities if such maps are used directly for statutory zoning within which planning controls are then exercised as has occurred in New Zealand [39]. Fortunately, it is common practice elsewhere to separately consider multiple SLR scenarios, e.g., $[10,18,40]$.

We have therefore applied the five uncertainty levels described by Walker et al. [23], and matched them to some of the uncertainty sources within a coastal hazard assessment in Table 2. Some or all of these levels of uncertainty will typically be involved in decision making in practice [21]. Walker et al. [21] used three descriptive terms to describe the level of uncertainty: statistical (level 2) and scenario (levels 3-4) uncertainty, and recognized ignorance (level 5). We use these terms in Section 4 to develop an 'uncertainty framework for coastal hazard assessment', because they are readily applicable to the treatment of SLR uncertainty. Deep uncertainty is defined as the situation where analysts do not know, or the parties to a decision cannot agree on, the appropriate conceptual models, the probability distributions used to represent uncertainty, and/or how to value the desirability of alternative outcomes [41]. Walker et al. [23] refer to level 4 and 5 uncertainties as deep uncertainty, and assign the do not know portion of the definition to level 5, and the cannot agree upon portion of the definition to level 4 uncertainties. SLR can be considered deeply uncertain towards the end of this century since experts cannot agree which of the scenarios (a multiplicity of unranked plausible futures, Table 2) is more likely and cannot assign relative probabilities to each RCP (due to multiple uncertainties such as, how emission policies, landuse, technological and socio-economic factors will evolve and the degree of response of polar ice sheets [18,31,42]). However, there is some evidence that the RCP2.6 scenario for SLR is increasingly unlikely [43], and so could be ranked as less likely than the other SLR scenarios (level 3 uncertainty, Table 2). Although not possible to assign statistical probabilities to future SLR, estimates have been made of the largest plausible projections of SLR by $2100[29,44]$.

Statistical probabilities can be calculated from the historical record for some hazard sources such as storm-tide, which equates to level 2 uncertainty. The frequency and magnitude of present-day storm tides (a combination of storm surge and high tide) can be modelled by fitting an extreme-value model to the historical observations of very high (e.g., annual maxima) sea-levels (Figure 1). The extreme-value model has a maximum-likelihood estimate (solid line in Figure 1), and a statistical uncertainty (level 2) around the maximum-likelihood estimate (dashed 95\% confidence intervals in Figure 1). Climate change may also alter the frequency and magnitude of storm tides in future, but there is recognized ignorance about exactly how this will occur, other than it is likely to be a second order effect compared to SLR. One solution is to undertake sensitivity tests for various hazard scenarios (leaving aside SLR) such as exploring $\pm 10 \%$ change, for example.

A challenge for coastal hazard assessment arises because the degree of uncertainty within individual hazard sources changes with time. Additionally, Le Cozannet et al. [45] showed that the relative importance of the various sources of uncertainties changes over the time-local coastal processes such as storm-tide and wave runup are the most important during the first part of this century, whereas uncertainties of future SLR scenarios largely dominate beyond the year 2080. In other words, level 2 statistical uncertainty is relatively important over short-term planning timeframes (before year 2060), but after a transition period (2060-2080), level 3-5 scenario and deep uncertainties become dominant over longer planning timeframes (after the year 2080), driven mainly by the increasing uncertainty in the rates of SLR [45]. For coastal hazard modeling, we suggest that uncertainty surrounding future rates of SLR must be dealt with by evaluating the hazard from various SLR 
scenarios (scenario uncertainty), and using higher $\mathrm{H}^{+}$type scenario(s), e.g., [46] as a proxy for exploring some implications of deep uncertainty in our understanding of the hazard from possible upper-range SLR, and evaluating their consequence within the DAPP [16]. This is the approach recommended within the 'uncertainty framework for coastal hazard assessment' in Section 4.

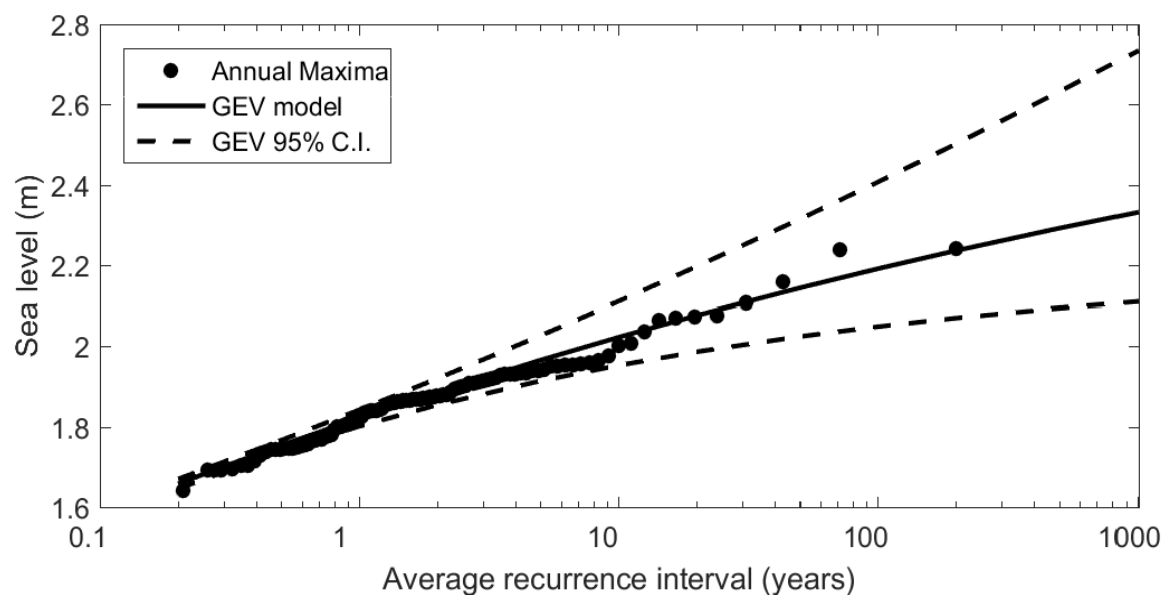

Figure 1. Generalized extreme-value model fitted to annual maxima sea level at Auckland, NZ. Dashed lines mark the 95\% confidence intervals (C.I.) (statistical uncertainty). Data supplied by Auckland Council.

The New Zealand Parliamentary Commissioner for the Environment recommended "in revising [New Zealand] central government direction and guidance on SLR, to specify that "best estimates" with uncertainty ranges for all parameters be used in technical assessments of coastal hazards" [47]. While it is desirable to specify statistical uncertainty ranges for some parameters, this may not always be possible. The longer the planning timeframe, the increasing dominance of SLR on the outcome [45], and neither a best estimate, nor statistical uncertainty, can be robustly derived for SLR $[18,29]$. In any case the optimal risk will occur at a higher SLR than the best estimate of the hazard, due to the tail in the probability distribution for SLR for any of the RCPs [12]. In such situations, the likelihood component of risk must be handled some other way, such as using adaptive approaches like the DAPP process $[16,19]$. With consequences for existing development rising non-linearly with increasing SLR, use of a "most likely" SLR (i.e., hazard exposure) is not commensurate with managing risk as required by the NZCPS. The DAPP process interactively embeds the likelihood or emergence aspect, where the time to reach pre-agreed decision or trigger points can be adjusted through regular monitoring and reviews as climate change effects and the ability to cope with them unfolds [16]. This is an appropriate way of addressing future coastal vulnerability and risk management in an adaptive manner, which will enable uncertainties to be worked around, rather than adapting now to a pre-determined future by selecting a best or likely SLR estimate or a "worst-case" scenario. 
Table 2. The five levels of uncertainty within the uncertainty framework described by Walker et al. [23], including descriptions of the uncertainty levels at the context and system-model locations. We have provided examples of how the uncertainty levels could be related to the treatment of SLR and other hazard sources within a coastal hazard assessment.

\begin{tabular}{|c|c|c|c|c|c|}
\hline Location & Level 1 & Level 2 & Level 3 & Level 4 & Level 5 \\
\hline Context [23] & $\begin{array}{l}\text { A clear enough future } \\
\text { (with sensitivity) }\end{array}$ & $\begin{array}{l}\text { Alternate futures } \\
\text { (with probabilities) }\end{array}$ & $\begin{array}{l}\text { Alternate futures } \\
\text { (with ranking) }\end{array}$ & $\begin{array}{l}\text { A multiplicity of plausible } \\
\text { futures (unranked) }\end{array}$ & Unknown future \\
\hline System model [23] & A single system model & $\begin{array}{c}\text { A single system model } \\
\text { with a probabilistic } \\
\text { parameterization }\end{array}$ & $\begin{array}{l}\text { Several system models, } \\
\text { one of which is } \\
\text { most likely }\end{array}$ & $\begin{array}{l}\text { Several system models, } \\
\text { with different structures }\end{array}$ & $\begin{array}{l}\text { Unknown system model, } \\
\text { know we don't know }\end{array}$ \\
\hline $\begin{array}{l}\text { SLR treatment within } \\
\text { coastal-hazard assessment }\end{array}$ & $\begin{array}{l}\text { Present-day MSL, or modest } \\
\text { SLR range for the next few } \\
\text { decades }(\leq 2050)\end{array}$ & $\begin{array}{c}\text { Probabilistic SLR } \\
\text { trajectories within a single } \\
\text { RCP scenario, e.g., [18] }\end{array}$ & $\begin{array}{c}\text { Rank one RCP SLR } \\
\text { scenarios relative to each } \\
\text { other, e.g., RCP2.6 now } \\
\text { considered unlikely [42] }\end{array}$ & $\begin{array}{l}\text { Treat all IPCC AR5 RCP } \\
\text { scenarios as separate and } \\
\text { equally plausible to } \\
\text { test pathways }\end{array}$ & $\begin{array}{l}\text { SLR rate at very long } \\
\text { timeframes not } \\
\text { considered in available } \\
\text { literature, e.g., beyond } \\
2150-2200\end{array}$ \\
\hline $\begin{array}{c}\text { Other hazard } \\
\text { source examples }\end{array}$ & $\begin{array}{l}\text { Median, or "best estimate" of } \\
\text { AEP, where calculable for } \\
\text { non-SLR coastal hazards, e.g., } \\
\text { storm-tide }\end{array}$ & $\begin{array}{c}\text { Statistical probabilities, } \\
\text { where calculable for } \\
\text { non-SLR coastal hazards, } \\
\text { e.g., storm-tide }\end{array}$ & & $\begin{array}{c}\text { An allowance for } \\
\text { increased future } \\
\text { storm-tide variability, } \\
\text { e.g., } \pm 10 \%\end{array}$ & $\begin{array}{l}\text { Geomorphic response to } \\
\text { SLR of tidal inlet/spit } \\
\text { systems on sand or } \\
\text { gravel shorelines }\end{array}$ \\
\hline $\begin{array}{l}\text { Coastal hazard } \\
\text { assessment situation }\end{array}$ & $\begin{array}{l}\text { Little uncertainty (or, } \\
\text { uncertainty is inconsequential } \\
\text { to decision being made, or } \\
\text { deliberately ignored) }\end{array}$ & $\begin{array}{l}\text { Statistical probabilities for } \\
\text { storm-tide or coastal } \\
\text { erosion based on } \\
\text { historical observations }\end{array}$ & \multicolumn{2}{|c|}{ SLR scenarios added to storm-tide probability levels } & $\begin{array}{l}\text { High SLR scenarios added } \\
\text { to present-day storm-tide } \\
\text { or coastal erosion } \\
\text { "best estimates" }\end{array}$ \\
\hline
\end{tabular}




\section{Location of Uncertainty Within Coastal Hazard Assessment}

Additional technical uncertainties are represented by the location dimension of the uncertainty matrix, and these can be highly scenario sensitive. These should also be made transparent to inform the DAPP process. That is, uncertainties located within the technical process of modeling the hazard, including the conceptual understanding of the processes, the data inputs, the structure and parameters used [21]. For example, coastal hazard assessment would ideally use a multi-hazard risk reduction approach, assessing risk from coastal erosion and flooding from tsunami as well as storm-tides and SLR. Furthermore, there can be complex interactions and responses to SLR between coastal flooding, erosion, and management interventions, e.g., [13,48,49]. For example, coastal erosion and flooding are connected [48], and beaches may erode, or may prograde under SLR when alongshore and sediment system coupling are considered, as up-drift cliffs supply sediment [13].

\section{Using Uncertainty to Guide Coastal Hazard Assessment}

A clear understanding of the uncertainties relevant to the decision being made can guide the approach to coastal hazard assessment. The framework shown in Figure 2 was developed to provide guidance to local government in New Zealand, when commissioning coastal hazard studies. It is designed to ensure that uncertainties are appropriately identified and managed, and for adequate hazard scenarios to be used in the DAPP process, which is a relatively new concept [16], and not yet commonly applied in New Zealand other than for a river delta flood situation [28]. Local government hazard analysts were concerned that without such a framework they may commission hazard studies that either do not meet the needs of the DAPP process, or are more complex and costly than required for the situation and decisions being considered (e.g., too many scenarios to model). Hence the framework in Figure 2 attempts to be specific about the hazard frequencies and magnitudes, statistical uncertainty and the SLR scenarios to consider, and for which types of activities to apply them, and thus to link back to the situational context and requirements. By also linking to the uncertainty types, the framework attempts to prevent the blurring between statistical and scenario uncertainty discussed in Section 3, or insufficient scenarios, which could lead to misinformed decision making and costly consequences if exposure increases and path dependency results.

The framework in Figure 2 shows relationships between the existing situation, the appropriate level of uncertainty that could be considered based on that situation, the coastal hazard assessment scenarios to match that level of uncertainty, and the associated hazard assessment modeling complexity. The framework attempts to provide logical flow paths from left to right, depicted by the arrows, that could guide the choice of hazard assessment scenarios, being cognizant of all stages within the hazard assessment; the land use situation, hazard modeling, and the decision-making process. For example, if the intention is to avoid a future hazard to a new development, then it is logical to follow the red boxes and account for recognized ignorance in the long-term rate of SLR beyond this century, by modeling high SLR values. However, there may be situations when it is practical to build new major infrastructure (e.g., highway) at low elevation, with staged adaptation planned to cope with future SLR, requiring a more comprehensive set of coastal hazard scenarios akin to adapting an existing development. Hence, Figure 2 draws a distinction, represented by the dashed arrows and dashed box, between the land use situation, the coastal hazard assessment modeling process, and the decision-making process. The eventual decision on whether and how to accept, adapt, or avoid the hazard, is informed by the coastal hazard assessment, but will also be influenced by other factors such as such as economic or social impact assessment [16] and the relevant statutory coastal planning policies (e.g., the NZCPS requires avoidance of increasing the risk from new development). 


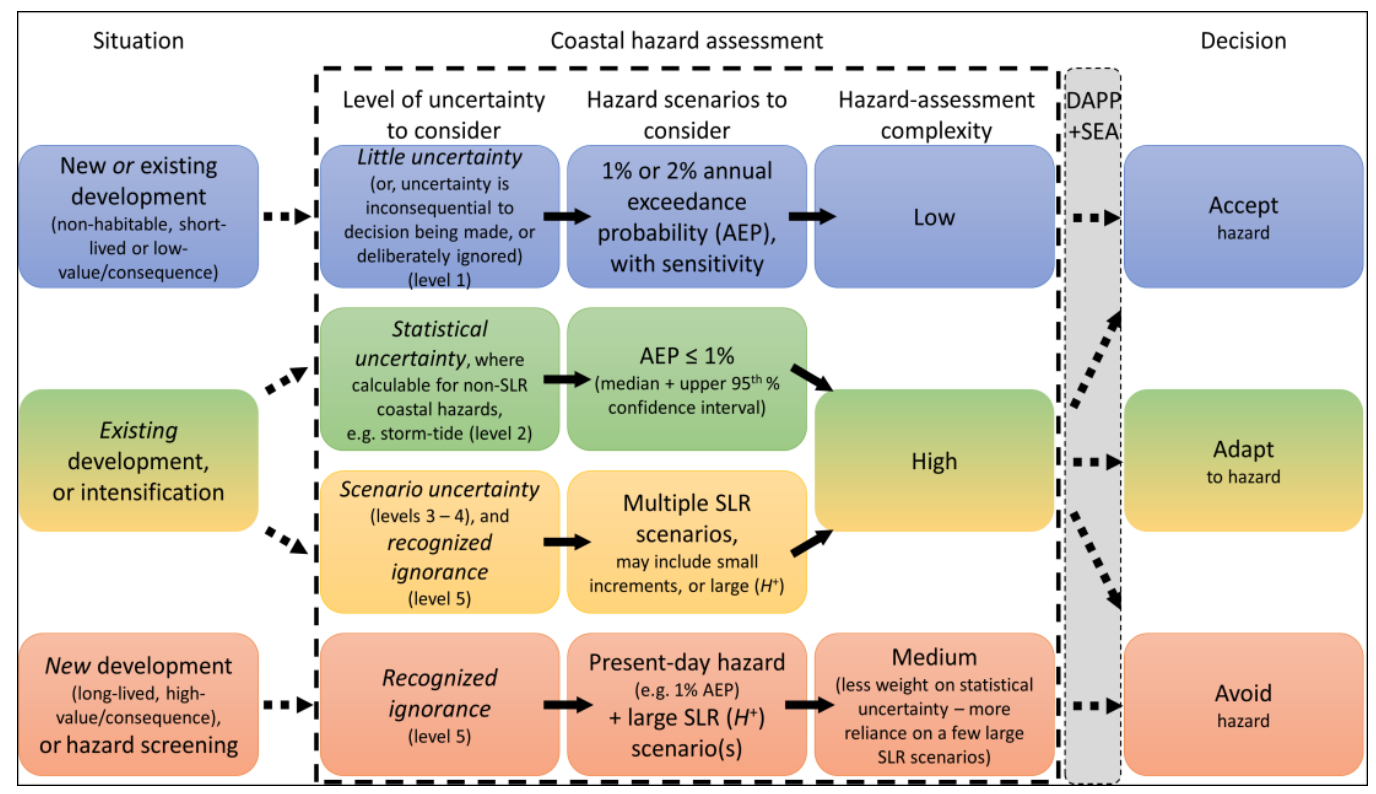

Figure 2. Uncertainty framework for coastal hazard assessments to support the DAPP process, showing a logical flow from the situation, to the related level of uncertainty as determined by the situation, the hazard scenarios to model, the likely hazard modeling complexity, and the possible decision type. A distinction is drawn (represented by the dashed arrows and dashed box) between the situation, the coastal hazard assessment process, the DAPP process and socio-economic assessment (SEA), and the decision type.

The framework in Figure 2 addresses three situations:

1. To avoid risk to new or existing development where, for non-habitable use, the risk of damage from coastal hazards and SLR is low, or the asset can be easily adapted to cope with future SLR. Although there may be high uncertainty around SLR in the long term, because the asset has a short life or low value, and has a functional need to be in the coastal margin, that uncertainty is inconsequential, or can be deliberately ignored. Examples might be a toilet block, a surf-lifesaving lookout, or a culvert supporting a minor access way. Such assets can be easily replaced or relocated, so modeling effort can be kept simple and low-cost. For example, using a simple "building block" model to allow for various coastal hazard sources, or relying on expert judgement or sensitivity testing to decide on an appropriate floor or culvert elevation or setback distance. The assumption in Figure 2 is that hazards are more likely to be accepted for non-habitable short-lived and/or low-value assets, although that decision will be influenced by the planning process, including socio-economic assessment.

2. The greatest demands on coastal hazard assessment are for existing, exposed developments, where ongoing adaptation will be required to cope with rising sea level. For avoiding risk to existing development, or for land use intensification or change in land use, the hazard assessment will require sufficient information to inform the decision(s) to be made, and, when intolerable or nuisance risks may emerge (if not already). This will require the use of both present-day statistical uncertainty (where calculable for non-SLR coastal hazards such as storm-tide), plus several SLR scenarios-thus, the hazard assessment is likely to be more complex and costly. Within the DAPP process, the hazard assessment will need to provide enough information to identify vulnerabilities and thresholds, to design adaptation pathways, and to identify trigger points for when to switch pathways before the threshold eventuates.

3. To avoid increasing the coastal risk exposure from new development and to test the longevity of the decision in establishing new developments on greenfield land where the logical and statutory requirement is to avoid future hazard (e.g., NZCPS); modeling effort can be kept relatively 
straightforward, focusing on an upper-range hazard scenario of at least the maximum-likelihood $1 \%$ annual exceedance probability (AEP) hazard plus a higher SLR scenario, e.g., the $H^{+}$SLR scenario (Section 2), or a higher percentile, e.g., [46].

The decision about whether to accept, adapt to, or avoid a hazard, can form a set of alternative pathways within the DAPP process. For example, a community might decide to accept a hazard in the short-term, until a trigger point is reached, after which they decide to adapt in some way, for example, by building a seawall, or shifting away from the coast. A range of adaptation pathways and a range of trigger points can be identified, e.g., [14]. There may be examples where a community must accept a hazard due to lack of resources or alternatives, or refuse to adapt, even though there may be considerable uncertainty surrounding future coastal hazard frequency and magnitude. The uncertainty framework provides guidance and supports assessment, but decision-makers make decisions based on many factors which they think appropriate. The hazard assessment and other evaluations such as economic and social impact assessments are only some of the decision inputs [16]. Nevertheless, all such decisions must still be made within the statutory framework operating in each jurisdiction or risk possible challenge.

Figure 3 provides a hypothetical example of three situations with different exposure to coastal hazards. We now use Figure 3 to explore how the framework in Figure 2 might apply to these three situations.

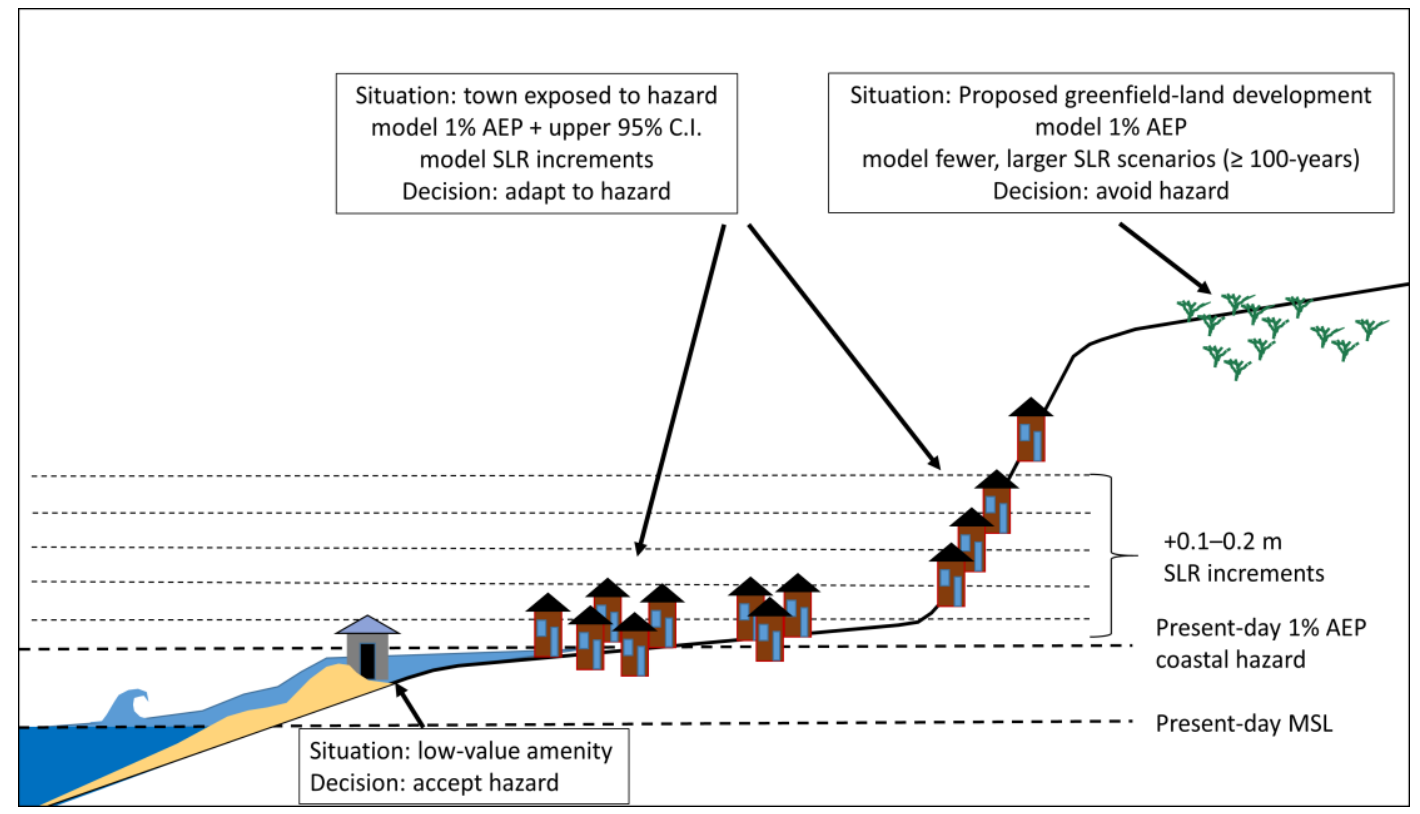

Figure 3. Choice of coastal hazard assessment model scenario based on hazard exposure. The degree of exposure indicates the level of uncertainty the coastal hazard assessment should address, the modeling scenarios required to assist decision making, and the likely complexity of the hazard assessment.

For communities that are already vulnerable to coastal hazards, it is likely that critical tipping points could be reached at relatively low SLR thresholds, such as for the town shown in Figure 3. The town is built on low-elevation land close to the coast and will need to adapt to coastal hazards with an early emergence of SLR impacts. The depth, extent, and frequency of the flooding and erosion hazards will grow incrementally with SLR, and tipping points (e.g., frequency of nuisance or damaging flooding or severe erosion events) may be reached well before $1 \mathrm{~m}$ of SLR occurs (which is often used as a single SLR scenario in hazard assessments). Areas on the hill slope will become progressively exposed as sea level rises incrementally. In this case, it would be useful to assess the impacts of a few regular small (e.g., 0.1-0.2 m) SLR height increments (on top of both the median and upper $95 \%$ of the 
$1 \%$ AEP flooding hazard) to identify potential tipping points and trigger points for input to the DAPP and the community engagement processes.

Where a new suburb is proposed to be built on a raised coastal platform approximately $1 \mathrm{~m}$ above present-day $1 \%$ AEP storm-tide level (Figure 3), hazard screening shows no exposure to $1 \%$ AEP coastal flooding or erosion at present-day MSL, but increasing hazard exposure after about $0.5 \mathrm{~m}$ or more of SLR from later this century. Coastal hazard assessment could instead focus on fewer SLR scenarios accounting for at least 100-year timeframes, such as $0.5 \mathrm{~m}, 1.0 \mathrm{~m}, H^{+}$SLR. Greenfields development in this suburb will require careful scrutiny to avoid increasing risk as the future unfolds.

The third situation involves accepting the hazard for a low-value public amenity, which was discussed in point 1 of this Section.

\section{A Coastal Flood Assessment Case Study to Support Dynamic Adaptive Policy Pathways}

This section provides a case study on different ways of presenting the coastal flood hazard. We then discuss the usefulness of the maps to the DAPP process.

Figure 4 presents an aerial photograph of Mission Bay, Auckland, New Zealand, along with results of a coastal flood assessment in the form of shaded areas representing the horizontal extent of the $1 \%$ AEP storm-tide plus wave setup elevation at: (i) present-day mean sea level (MSL); (ii) present-day MSL + $1 \mathrm{~m}$ SLR; and (iii) present-day MSL + $2 \mathrm{~m}$ SLR. These types of hazard maps provide a useful summary for planning authorities, showing both the present-day hazard, and identifying the potential future hazard for at least a 100-year timeframe, as required under the statutory NZCPS. Maps such as these formed the basis for development controls in the Auckland Region [50].

Although useful, such hazard-exposure maps in Figure 4 have several limitations:

- They show land either as 'in' or 'out' of the hazard area, but provide no information of the gradient in hazard magnitude away from the sea (e.g., a property at the landward edge of the $1 \%$ AEP $+1 \mathrm{~m}$ SLR area will only be affected towards the end of the 100-year planning timeframe);

- They provide no information on the timing of the emerging hazard;

- They provide no information on the increasing frequency of flooding with future SLR;

- The hazard analysis for the $+1 \mathrm{~m}$ and $+2 \mathrm{~m}$ SLR scenarios may not be useful for adaptation planning if flooding begins to occur frequently at lower SLR.

The analysis in Figure 4 also acts as a hazard screening tool, showing that much of Mission Bay could be affected by flooding after $+1 \mathrm{~m}$ SLR, and, similar to the town in Figure 3, parts of Mission Bay are likely to reach tipping points before $+1 \mathrm{~m}$ of SLR occurs.

The uncertainty framework in Figure 2 suggests that for such locations, the impacts of regular small $(0.1-0.2 \mathrm{~m})$ SLR height increments should be assessed (on top of both the median and upper $95 \%$ of the $1 \%$ AEP hazard) to identify potential trigger points for input to the DAPP and community engagement processes.

Figure 5 uses a static mapping technique to add $0.1 \mathrm{~m}$ SLR increments directly on top of the present-day median (maximum-likelihood) $1 \%$ AEP storm-tide elevation, working under the common assumption that the dominant effect changing the depth of flooding events will be SLR [11,51-53], and ignoring changing storm characteristics. Figure 5 provides more detail than Figure 4, and clearly indicates how flooding extent might change incrementally with SLR, depending on location. Similar mapping products are available in New Zealand ${ }^{1}$ and overseas ${ }^{2}$. Properties on low-elevation land close to the sea will face flooding after a modest SLR, so will be affected sooner. Properties located further inland on higher elevation land are less exposed and will have longer to adapt to rising sea level. Such maps also assist councils to assess the emergence of risks to roads and other utilities 
and services. The mapping of small SLR increments will be more useful for adaptation planning, as it relates a gradually increasing flooding extent to gradually increasing SLR. However, as with Figure 4, Figure 5 provides no information on the depth and frequency of flooding.

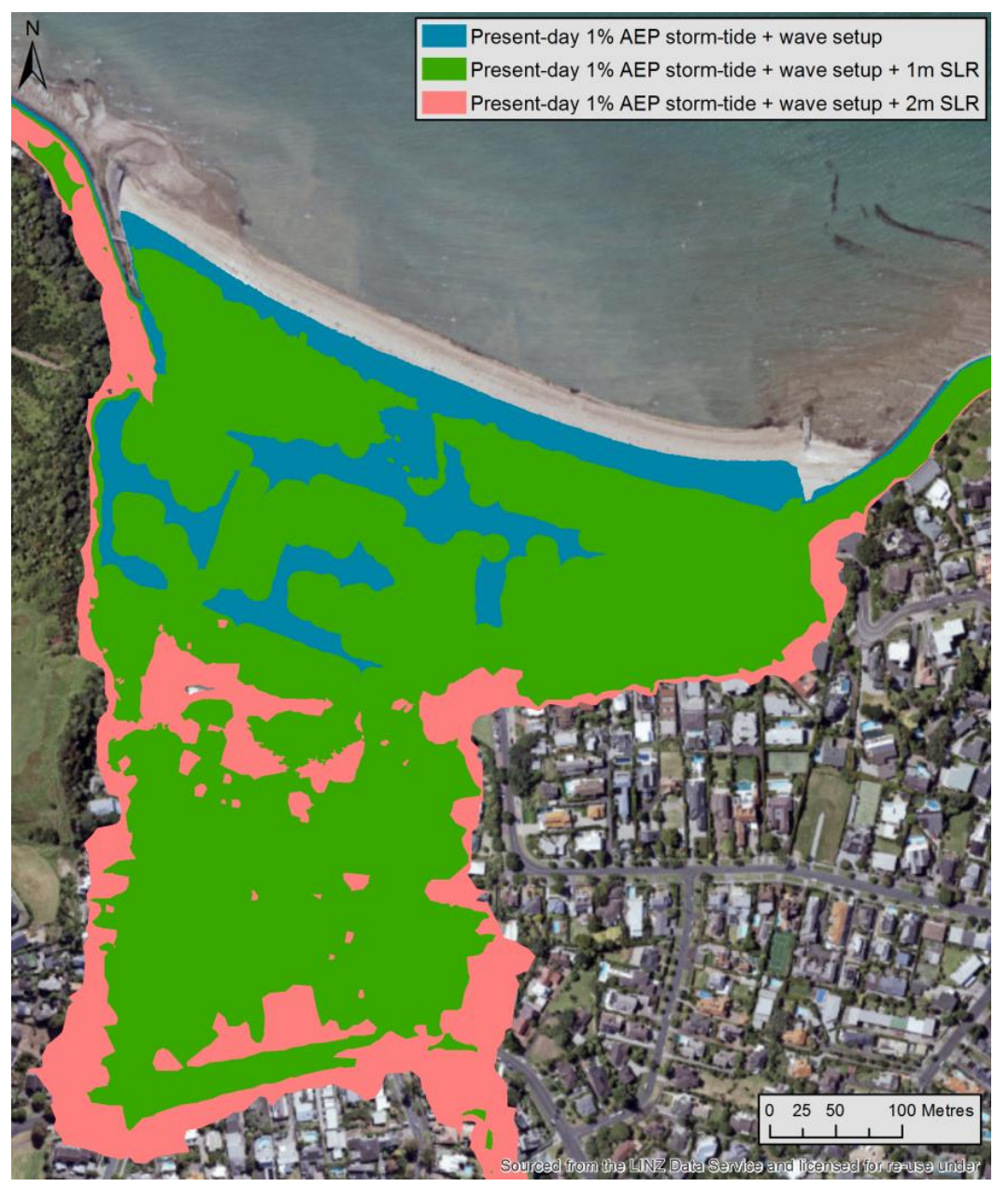

Figure 4. Coastal-storm flood mapping example at Mission Bay, Auckland. Aerial photograph of Mission Bay with present-day 1\% AEP storm-tide plus wave setup elevation superimposed (blue shading), plus $1 \mathrm{~m}$ SLR (green shading), and plus 2 m SLR (pink shading). After: (50 @Engineers Australia, 2015).

Figures 6 and 7 provide even more information, mapping the expected depth and frequency of flooding for various SLR scenarios, again assuming that SLR will dominate the future increase in flooding frequency. Another example is NOAA's online sea-level rise viewer (https:/ / coast.noaa.gov/slr), which maps flooding depth for various SLR scenarios.

Figure 6 shows the depth (and area) of flooding for a 1\% AEP storm-tide at present-day MSL, plus $0.8 \mathrm{~m}$ SLR scenario. The map shows the increasing area and depth (severity) of future flooding as the sea rises. The changing frequency of flooding was determined by vertically translating the empirical sea-level distribution to account for SLR, e.g., [10]. The sea-level distribution was first merged with an extreme-value model to create a mixed-distribution model, which represented the full sea-level distribution [9].

Figure 7 shows the frequency (and area) of flooding for a 1\% AEP storm-tide at present-day MSL, plus $0.8 \mathrm{~m}$ SLR scenario. The map shows that coastal-storm flooding becomes increasingly likely with SLR. In combination, Figures 6 and 7 show both the expected depth and frequency of future flooding. 


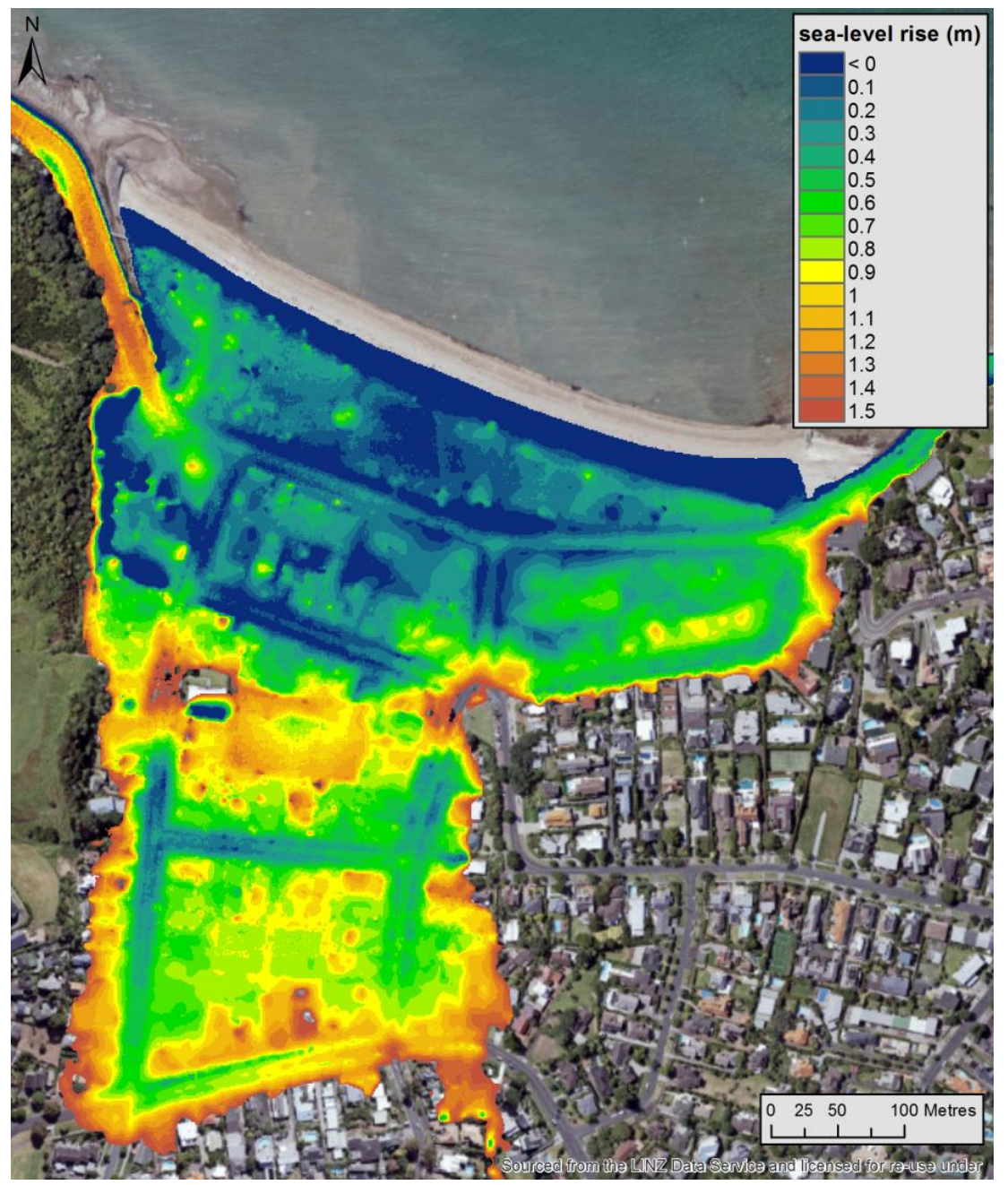

Figure 5. The effect of $0.1 \mathrm{~m}$ SLR increments on coastal-storm flood exposure at Mission Bay (Auckland). SLR increments have been added onto the $1 \%$ AEP storm-tide elevation, which was calculated for the present-day mean sea level.

The combination of these plots (Figures 6 and 7) provides information that is more useful for decision making than any of the other plots in isolation. For example, a property located beside the first street back from the sea is not presently exposed, but after $0.8 \mathrm{~m}$ SLR can be expected to be inundated by about $0.5 \mathrm{~m}$ or more of water, about 10 times per year. Clearly the owner of this property will face a tipping point before $0.8 \mathrm{~m}$ of SLR occurs, and certainly well before 1.0 or $2.0 \mathrm{~m}$ SLR occurs. Understanding the additional information that Figures 6 and 7 portray can enable decision makers to design trigger points ahead of intolerable damage occurring and design longer term strategies for managing the transition for the existing developments (NZCPS) ${ }^{3}$.

Figures 6 and 7 were created using a static mapping technique within GIS, which does not consider the dynamic route of flooding nor connectivity to the sea. For example, there are red areas in Figure 7 showing "islands" of 365 daily exceedances per year, which may not occur. These "islands" might be connected to the sea through culverts, and can be identified and used to adjust the areas shown as flooded in the static maps. Dynamic models, which are more computationally expensive, could also

3 NZCPS Policy 27 I (e) identifying and planning for transition mechanisms and timeframes for moving to more sustainable approaches. 
have been used to create more accurate maps. However, the spatially varying frequency and depth of flooding can be mapped irrespective of the mapping technique.

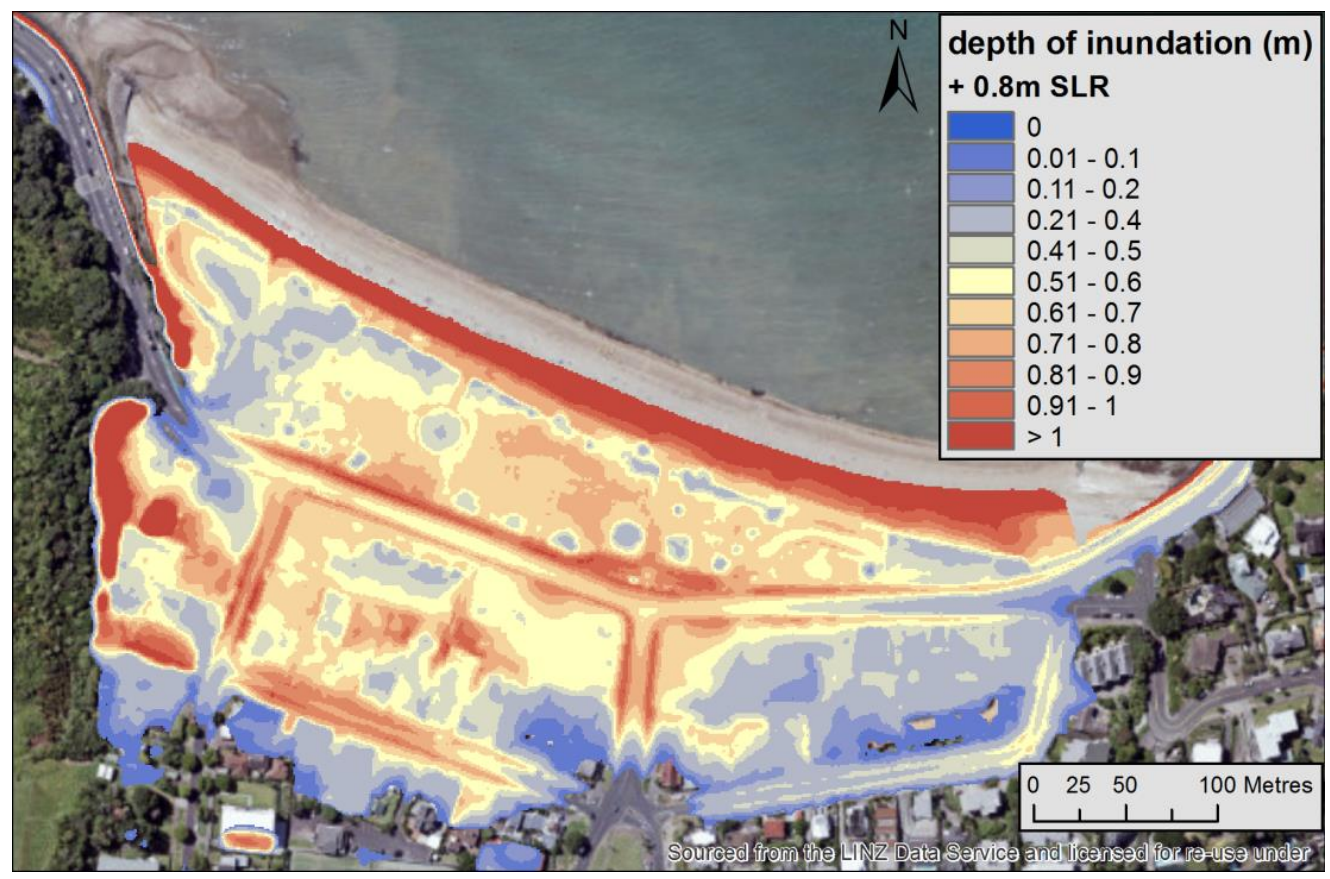

Figure 6. Depth of flooding at Mission Bay, Auckland, for a 1\% AEP storm-tide at present-day MSL $+0.8 \mathrm{~m}$ SLR. Flooding was modelled using a static GIS technique. All areas below the modelled sea level are shown as inundated, regardless of connection to the sea-some inland areas may not become inundated as shown if such interconnections exist.

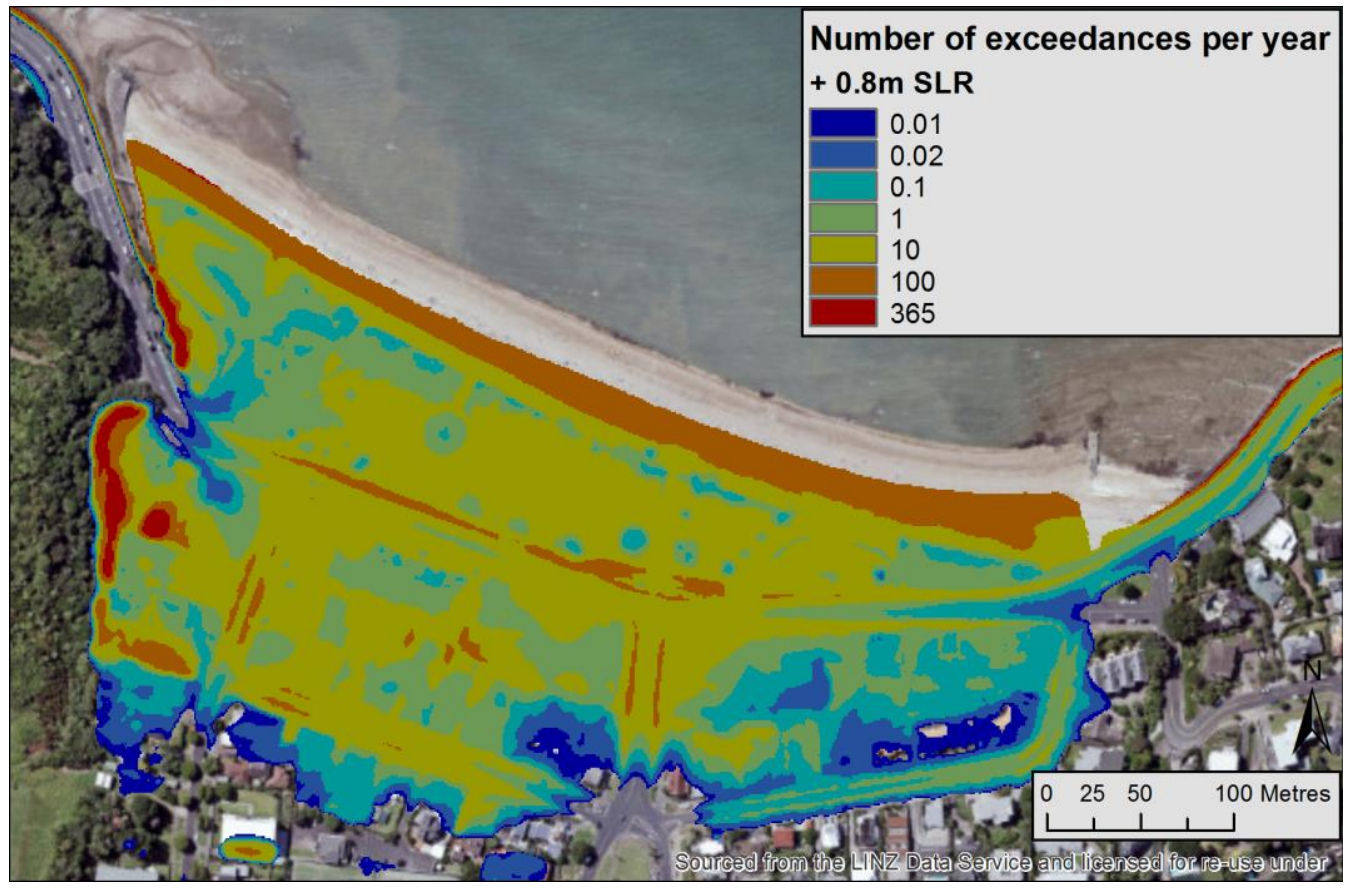

Figure 7. Frequency of flooding (exceedances per year) at Mission Bay, Auckland, for a 1\% AEP storm-tide, at present-day MSL + 0.8 m SLR. Flooding was modelled using a static GIS technique. All areas below the modelled sea level are shown as inundated, regardless of connection to the sea-some inland areas may not become inundated as shown if such interconnections exist. 
The final piece of the puzzle is to identify the likely timing of the various flooding scenarios mapped in Figures 6 and 7, which can be achieved using Table 1. In Section 6, we have provided a hypothetical example to demonstrate the intended use of the uncertainty framework (Figure 2), the maps (Figures 6 and 7), and possible SLR timing (Table 1) within a DAPP process.

\section{Applying the Uncertainty Framework within the DAPP Process}

This hypothetical example illustrates how the uncertainty framework might be used in a DAPP process:

1. A community living in the town shown in Figure 3 (or Figures 4-7) decides to proceed with a DAPP process before further development occurs. Such planning fulfils the requirement in the NZCPS for risk-based planning. There is also general agreement within the community (established through a community engagement process and council knowledge) that the planning is required, based on existing coastal flooding problems in some areas, plus an existing simple hazard assessment and expert opinion that show increasing flooding depth with SLR.

2. The local council, which is responsible for planning to reduce or avoid risk from climate change, commission a detailed coastal hazard study. Based on the uncertainty framework (Figure 2), the hazard study estimates the flood height from a storm-tide with a present-day likelihood of flooding of $1 \%$ AEP, plus the upper $95 \%$ confidence interval of the $1 \%$ AEP estimate. The effect of SLR is assessed by adding $0.1 \mathrm{~m}$ increments up to $0.5 \mathrm{~m}$, onto the present-day $1 \%$ AEP estimate. A higher SLR of $+1 \mathrm{~m}$ is also assessed to provide a longer-term scenario consistent with a 100-year planning timeframe, e.g., [50], and an $H^{+}$SLR scenario of $+1.9 \mathrm{~m}$ by 2150 (Table 1 ) is assessed for the purposes of risk avoidance for greenfields development within the town.

3. The hazard scenarios are mapped, and the maps show both the areal extent, the depth, and the expected frequency of flooding, as in Figures 6 and 7, and how the flooding area, depth and frequency change with the SLR scenarios.

4. The community then meets with the council, and the hazard maps for the various scenarios are presented and explained. The maps form the basis of a discussion whereby the community identifies vulnerable assets, and identifies tipping point scenarios where the depth and frequency of flooding of those assets (i.e., consequences) would become unacceptable if no action were taken, and therefore adaptation is required. Thus, when applying the framework, the consequences have been separated from the likelihood of occurrence, and the community initially makes decisions based primarily on consequence.

5. The possible timing of those scenarios is then assessed using Table 1. Thus, given that the likelihood of future SLR scenarios is unknown, Table 1 brackets the possible earliest and latest timing of consequences. There is a clear separation between the statistical uncertainty associated with the storm-tide estimates and the various SLR scenarios, which provides clarity to the decision-making process. Community understanding of the flooding risk can be further enhanced by using images of historical damaging coastal flooding (when available), to provide a visual representation of present-day statistical likelihood.

6. The community, with assistance from practitioners, uses the knowledge of the depth, frequency and timing to decide on several pre-determined courses of action (adaptation pathways). Those pathways could include staged alternative strategies such as coastal protection, building modifications, retreat from the coast, and avoidance of greenfields development. Planning provisions to control future development can form supporting strategies to avoid further lock-in of the current pathway. The community identifies potential trigger points, for example, based on a frequency of flooding of a given depth that is not tolerable, which identifies when a switch between pathways needs to occur. They then monitor and review the situation over time using the specified triggers in an iterative fashion as the physical and socio-economic conditions change. 
Haasnoot et al. [14] and Lawrence and Haasnoot [28] provide specific examples of a DAPP process in action. The coastal hazard uncertainty framework provided here can add to such empirical examples in future.

\section{Discussion and Conclusions}

Coastal flooding has caused periodic damage, nuisance flooding or disruption in the past. On the back of rising sea levels, these hazards will greatly increase in frequency, depth and consequence in the future. Coastal hazard assessments require more clarity of hazard-exposure information in a way that uncertainty and dynamics of change are clearly understood, to better assist decision-making and community engagement processes.

The DAPP process involves the identification of trigger points, whereby communities decide ahead of time on potential courses of action or pathways for when those trigger points are reached. Coastal hazard assessments must therefore clearly assist communities and councils (in relation to specified levels of service) to decide what those trigger points are, by providing alternative scenarios along with the likely time range for those scenarios. This requires a careful treatment of uncertainty, because there are different levels of uncertainty that come into play when dealing with the long timeframes and progressive hazards associated with SLR. These sources of uncertainty need to be carefully separated out and communicated transparently.

For coastal hazard assessment, multiple uncertainty levels can be addressed by calculating statistical uncertainties for coastal hazards at present-day mean sea level, evaluating the additional hazard from various SLR increments (scenario uncertainty), and using high $\mathrm{H}^{+}$SLR scenarios to explore the implications of deep uncertainty about the hazard from possible upper-range SLR, and evaluating their consequence within the DAPP.

We developed an 'uncertainty framework for coastal hazard assessment', designed to guide local government when commissioning coastal hazard assessments to assist the dynamic adaptive policy pathways process. The framework provides a logical flow from the landuse situation, to the related level of uncertainty as determined by the situation, to which hazard scenarios to model, to the complexity of hazard modeling required, and to the possible decision type.

A case study illustrates how coastal hazard exposure can be mapped for small increments of SLR. Such increments represent a range of plausible future scenarios, which can be superimposed on high storm-tide elevations for which there is an estimated statistical likelihood. The mapping of small SLR increments will be useful for adaptation planning, as it relates a gradually increasing flooding extent to gradually increasing SLR. This can inform communities and councils on when intolerable hazard exposure and risk may emerge (in relation to a SLR and event frequency trigger, and using the bracketed time windows in Table 1).

Maps of coastal flooding typically show just the area of flooding, but we have demonstrated how these can be improved to also show the depth and expected frequency of flooding. This extra information is useful for decision making, showing the degree of exposure, where that exposure occurs, and as input to how much sea-level rise can be tolerated. When combined with information on the approximate bracketed timing of the incremental sea-level rise scenarios, the maps allow communities, stakeholders and councils to identify trigger points and expected earliest time for the emergence of intolerable flooding risk. The actual progression of SLR, and of the triggers before objectives are no longer met, can then be monitored and reviewed. The 'uncertainty framework for coastal hazard assessment' enhances adaptation practice by enabling more salient decision making, because there is greater clarity in the treatment of uncertainty and dynamic aspects of the future risks, which to date have become barriers to the implementation of long-term path dependency considerations in current planning practice.

Acknowledgments: The project was funded by the New Zealand Ministry of Business, Innovation and Employment under Strategic Investment Fund projects CAFS1703 and CAVA1704 of the National Institute of Water 
and Atmospheric Research. Sanjay Wadhwa produced the flood maps. Aerial imagery sourced from LINZ Data Service and licensed for re-use under the Creative Commons Attribution 3.0 New Zealand license. Manuscript reviews by Mark Dickson, an anonymous reviewer, and the academic editor improved the final version.

Author Contributions: Stephens and Bell conceived the mapping concepts, which were applied within a national guidance document on which all three authors collaborated [54]. Lawrence introduced us to Walker's work on uncertainty [21], to Haasnoot's work on DAPP [16]. Bell developed Table 1. Stephens conceived the 'uncertainty framework for coastal hazard assessment', which was revised collaboratively by the authors. Stephens wrote the paper with input from Bell and Lawrence.

Conflicts of Interest: The authors declare no conflict of interest. The funding sponsors had no role in the design of the study; in the collection, analyses, or interpretation of data; in the writing of the manuscript, and in the decision to publish the results.

\section{References}

1. Schwartz, M.L. Encyclopaedia of Coastal Science; Springer: Dordrecht, The Netherlands, 2005.

2. Kopp, R.E.; Kemp, A.C.; Bittermann, K.; Horton, B.P.; Donnelly, J.P.; Gehrels, W.R.; Hay, C.C.; Mitrovica, J.X.; Morrow, E.D.; Rahmstof, S. Temperature-driven global sea-level variability in the Common Era. Proc. Natl. Acad. Sci. USA 2016, 113, E1434-E1441. [CrossRef] [PubMed]

3. Hinkel, J.; Lincke, D.; Vafeidis, A.T.; Perrette, M.; Nicholls, R.J.; Tole, R.S.J.; Marzeion, B.; Fettweis, X.; Ionescu, C.; Levermann, A. Coastal flood damage and adaptation costs under 21st century sea-level rise. Proc. Natl. Acad. Sci. USA 2014, 111, 3292-3297. [CrossRef] [PubMed]

4. Nicholls, R.J.; Marinova, N.; Lowe, J.A.; Brown, S.; Vellinga, P.; de Gusmão, D.; Hinkel, J.; Tol, R.S.J. Sea-level rise and its possible impacts given a 'beyond $4{ }^{\circ} \mathrm{C}$ world' in the twenty-first century. Philos. Trans. R. Soc. A Math. Phys. Eng. Sci. 2011, 369, 161-181. [CrossRef] [PubMed]

5. Church, J.A.; Clark, P.U.; Cazenave, A.; Gregory, J.M.; Jevrejeva, S.; Levermann, A.; Merrifield, M.A.; Milne, G.A.; Nerem, R.S.; Nunn, P.D.; et al. Climate Change 2013: The Physical Science Basis. Contribution of Working Group I to the Fifth Assessment Report of the Intergovernmental Panel on Climate Change; Stocker, T.F., Qin, D., Plattner, G.-K., Tignor, M., Allen, S.K., Boschung, J., Nauels, A., Xia, Y., Bex, V., Midgley, P.M., Eds.; Cambridge University Press: Cambridge, UK, 2013; pp. 1137-1216.

6. $\quad$ Pachauri, R.K.; Allen, M.R.; Barros, V.R.; Broome, J.; Cramer, W.; Christ, R.; Church, J.A.; Clarke, L.; Dahe, Q.; Dasgupta, P.; et al. Climate change 2014: Synthesis Report. Contribution of Working Groups I, II and III to the Fifth Assessment Report of the Intergovernmental Panel on Climate Change; Pachauri, R., Meyer, L., Eds.; IPCC: Geneva, Switzerland, 2014; 151p.

7. Nicholls, R.J.; Cazenave, A. Sea-Level Rise and Its Impact on Coastal Zones. Science 2010, 328, 1517-1520. [CrossRef] [PubMed]

8. Parlimentary Commissioner for the Environment (PCE). Changing Climate and Rising Seas: Understanding the Science; New Zealand Parlimentary Commissioner for the Environment Report; Parlimentary Commissioner for the Environment: Wellington, New Zealand, 2014; p. 56.

9. Stephens, S.A. The Effect of Sea-Level Rise on the Frequency of Extreme Sea Levels in New Zealand; NIWA Client Report to the Parlimentary Commissioner for the Environment; No. HAM2015-090; National Institute of Water and Atmospheric Research: Hamilton, New Zealand, 2015; p. 52.

10. Sweet, W.V.; Park, J. From the extreme to the mean: Acceleration and tipping points of coastal inundation from sea level rise. Earths Future 2014, 2, 579-600. [CrossRef]

11. Hunter, J.R. A simple technique for estimating an allowance for uncertain sea-level rise. Clim. Chang. 2012, 113, 239-252. [CrossRef]

12. Slangen, A.B.A.; van de Wal, R.S.W.; Reerink, T.J.; de Winter, R.C.; Hunter, J.R.; Woodworth, P.L.; Edwards, T. The Impact of Uncertainties in Ice Sheet Dynamics on Sea-Level Allowances at Tide Gauge Locations. J. Mar. Sci. Eng. 2017, 5, 21. [CrossRef]

13. Dickson, M.; Walkden, M.; Hall, J. Systemic impacts of climate change on an eroding coastal region over the twenty-first century. Clim. Chang. 2007, 84, 141-166. [CrossRef]

14. Haasnoot, M.; Schellekens, J.; Beersma, J.J.; Middelkoop, H.; Kwadijk, J.C.J. Transient scenarios for robust climate change adaptation illustrated for water management in The Netherlands. Environ. Res. Lett. 2015, 10, 105008. [CrossRef] 
15. Werners, S.E.; Pfenninger, S.; van Slobbe, E.; Haasnoot, M.; Kwakkel, J.H.; Swart, R.J. Thresholds, tipping and turning points for sustainability under climate change. Curr. Opin. Environ. Sustain. 2013, 5, 334-340. [CrossRef]

16. Haasnoot, M.; Kwakkel, J.H.; Walker, W.E.; ter Maat, J. Dynamic adaptive policy pathways: A method for crafting robust decisions for a deeply uncertain world. Glob. Environ. Chang. 2013, 23, 485-498. [CrossRef]

17. Ministry for the Environment (MfE). Coastal Hazards and Climate Change: A Guidance Manual for Local Government in New Zealand, 2nd ed.; Ramsay, D., Bell, R., Eds.; Ministry for the Environment: Wellington, New Zealand, 2008.

18. Kopp, R.E.; Horton, R.M.; Little, C.M.; Mitrovica, J.X.; Oppenheimer, M.; Rasmussen, D.J.; Strauss, B.H.; Tebaldi, C. Probabilistic 21st and 22nd century sea-level projections at a global network of tide-gauge sites. Earths Future 2014, 2, 383-406. [CrossRef]

19. Bell, R.G.; Lawrence, J.; Stephens, S.A.; Allan, S.; Blackett, P.; Lemire, E.; Zwartz, D. Coastal Hazards and Climate Change: New Zealand Guidance. In Proceedings of the Australasian Coasts \& Ports Conference 2017, Carins, Australia, 21-23 June 2017.

20. Lawrence, J.; Sullivan, F.; Lash, A.; Ide, G.; Cameron, C.; McGlinchey, L. Adapting to changing climate risk by local government in New Zealand: Institutional practice barriers and enablers. Local Environ. 2015, 20, $298-320$. [CrossRef]

21. Walker, W.E.; Harremoës, P.; Rotmans, J.; van der Sluijs, J.P.; van Asselt, M.B.A.; Janssen, P.; Krayer von Krauss, M.P. Defining Uncertainty: A Conceptual Basis for Uncertainty Management in Model-Based Decision Support. Integr. Assess. 2003, 4, 5-17. [CrossRef]

22. Kwakkel, J.H.; Walker, W.E.; Marchau, V.A.W.J. Classifying and communicating uncertainties in model-based policy analysis. Int. J. Technol. Policy Manag. 2010, 10, 299-315. [CrossRef]

23. Walker, W.E.; Lempert, R.J.; Kwakkel, J.H. Deep Uncertainty. In Encyclopedia of Operations Research and Management Science; Gass, S., Fu, M.C., Eds.; Springer: New York, NY, USA, 2013; pp. 395-402.

24. Kwakkel, J.H.; Walker, W.E.; Marchau, V.A.W.J. Adaptive airport strategic planning. Eur. J. Transp. Infrastruct. Res. 2010, 10, 249-273.

25. Walker, W.E.; Rahman, S.A.; Cave, J. Adaptive policies, policy analysis, and policy-making. Eur. J. Oper. Res. 2001, 128, 282-289. [CrossRef]

26. Haasnoot, M.; Middelkoop, H.; Offermans, A.; van Beek, E.; van Deursen, W.P.A. Exploring pathways for sustainable water management in river deltas in a changing environment. Clim. Chang. 2012, 115, 795-819. [CrossRef]

27. Kwadijk, J.C.J.; Haasnoot, M.; Mulder, J.P.M.; Hoogvliet, M.M.C.; Jeuken, A.B.M.; van der Krogt, R.A.A.; van Oostrom, N.G.C.; Schelfhout, H.A.; van Velzen, E.H.; van Waveren, H.; et al. Using adaptation tipping points to prepare for climate change and sea level rise: A case study in the Netherlands. Wiley Interdiscip. Rev. Clim. Chang. 2010, 1, 729-740. [CrossRef]

28. Lawrence, J.; Haasnoot, M. What it took to catalyse uptake of dynamic adaptive pathways planning to address climate change uncertainty. Environ. Sci. Policy 2017, 68, 47-57. [CrossRef]

29. Jevrejeva, S.; Grinsted, A.; Moore, J.C. Upper limit for sea level projections by 2100. Environ. Res. Lett. 2014, 9, 104008. [CrossRef]

30. Ruckert, K.L.; Oddo, P.C.; Keller, K. Impacts of representing sea-level rise uncertainty on future flood risks: An example from San Francisco Bay. PLoS ONE 2017, 12, e0174666. [CrossRef] [PubMed]

31. Slangen, A.B.A.; Adloff, F.; Jevrejeva, S.; Leclercq, P.W.; Marzeion, B.; Wada, Y.; Winkelmann, R. A Review of Recent Updates of Sea-Level Projections at Global and Regional Scales. Surv. Geophys. 2017, 38, 385-406. [CrossRef]

32. DeConto, R.M.; Pollard, D. Contribution of Antarctica to past and future sea-level rise. Nature 2016, 531, 591-597. [CrossRef] [PubMed]

33. Ackerley, D.; Bell, R.G.; Mullan, A.B.; McMillan, H. Estimation of regional departures from global-average sea-level rise around New Zealand from AOGCM simulations. Weather Clim. 2013, 33, 2-22.

34. Horton, R.; Bader, D.; Kushnir, Y.; Little, C.; Blake, R.; Rosenzweig, C. New York City Panel on Climate Change 2015 Report. Chapter 1: Climate Observations and Projections. Ann. N. Y. Acad. Sci. 2015, 1336, 18-35. [CrossRef] [PubMed]

35. Cowell, P.J.; Thorn, B.G.; Jones, R.A.; Everts, C.H.; Simanovic, D. Management of uncertainty in predicting climate-change impacts on beaches. J. Coast. Res. 2006, 22, 232-245. [CrossRef] 
36. Ramsay, D.L.; Gibberd, B.; Dahm, J.; Bell, R.G. Defining Coastal Hazard Zones and Setback Lines. A Guide to Good Practice; Envirolink Tools Report R3-2 NIWA: Hamilton, New Zealand, 2012; 91p. Available online: http:/ / www.envirolink.govt.nz/Envirolink-tools / (accessed on 26 August 2017).

37. Tonkin and Taylor Ltd. Coastal Hazard Assessment. Stage 2; Client Report to Christchurch City Council; 851857.001.v2.1; Tonkin and Taylor Ltd.: Auckland, New Zealand, 2015.

38. Tonkin and Taylor Ltd. Coastal Flood Hazard Zones for Selected Northland Sites; Client Report to Northland Regional Council; 30524.v1; Tonkin and Taylor Ltd.: Auckland, New Zealand, 2016.

39. Kenderdine, S.E.; Hart, D.E.; Cox, R.J.; de Lange, W.P.; Smith, M.H. Peer Review of the Christchurch Coastal Hazards Assessment Report; Review report produced for the Christchurch City Council; Christchurch City Council: Christchurch, New Zealand, 2016; 74p.

40. Buchanan, M.K.; Michael, O.; Robert, E.K. Amplification of flood frequencies with local sea level rise and emerging flood regimes. Environ. Res. Lett. 2017, 12, 064009. [CrossRef]

41. Lempert, R.J.; Popper, S.W.; Bankes, S.C. Shaping the Next One Hundred Years: New Methods for Quantitative, Long-Term Policy Analysis; Rand Corporation: Santa Monica, CA, USA, 2003.

42. City and County of San Francisco Sea Level Rise Committee. Guidance for Incorporating Sea Level Rise into Capital Planning in San Francisco: Assessing Vulnerability and Risk to Support Adaptation; San Francisco Department of the Environment: San Francisco, CA, USA, 2015.

43. Magnan, A.K.; Colombier, M.; Billé, R.; Joos, F.; Hoegh-Guldberg, O.; Pörtner, H.-O.; Waisman, H.; Spencer, T.; Gattuso, J.-P. Implications of the Paris agreement for the ocean. Nat. Clim. Chang. 2016, 6, 732-735. [CrossRef]

44. Le Cozannet, G.; Manceau, J.-C.; Rohmer, J. Bounding probabilistic sea-level projections within the framework of the possibility theory. Environ. Res. Lett. 2017, 12, 014012. [CrossRef]

45. Le Cozannet, G.; Rohmer, J.; Cazenave, A.; Idier, D.; van de Wal, R.; de Winter, R.; Pedreros, R.; Balouin, Y.; Vinchon, C.; Oliveros, C. Evaluating uncertainties of future marine flooding occurrence as sea-level rises. Environ. Model. Softw. 2015, 73, 44-56. [CrossRef]

46. Sweet, W.V.; Kopp, R.E.; Weaver, C.P.; Obeysekera, J.; Horton, R.M.; Thieler, E.R.; Zervas, C. Global and regional sea level rise scenarios for the United States. In NOAA Technical Report NOS CO-OPS 083; National Oceanic and Atmospheric Administration: Washington, DC, USA, 2017; 75p.

47. Parliamentary Commissioner for the Environment (PCE). Preparing New Zealand for Rising Seas: Certainty and Uncertainty; Parliamentary Commissioner for the Environment: Wellington, New Zealand, 2015; p. 92.

48. Dawson, R.J.; Dickson, M.E.; Nicholls, R.J.; Hall, J.W.; Walkden, M.J.A.; Stansby, P.K.; Mokrech, M.; Richards, J.; Zhou, J.; Milligan, J.; et al. Integrated analysis of risks of coastal flooding and cliff erosion under scenarios of long term change. Clim. Chang. 2009, 95, 249-288. [CrossRef]

49. Stive, M.J.F. How Important is Global Warming for Coastal Erosion? Clim. Chang. 2004, 64, 27-39. [CrossRef]

50. Stephens, S.A.; Bell, R.G. Planning for coastal-storm inundation and sea-level rise. In Proceedings of the Australasian Coasts \& Ports Conference 2015, Auckland, New Zealand, 15-18 September 2015.

51. Tebaldi, C.; Strauss, B.H.; Zervas, C.E. Modelling sea level rise impacts on storm surges along US coasts. Environ. Res. Lett. 2012, 7, 014032. [CrossRef]

52. Hunter, J.R. Estimating sea-level extremes under conditions of uncertain sea-level rise. Clim. Chang. 2010, 99, 331-350. [CrossRef]

53. Buchanan, M.K.; Kopp, R.E.; Oppenheimer, M.; Tebaldi, C. Allowances for evolving coastal flood risk under uncertain local sea-level rise. Clim. Chang. 2016, 137, 347-362. [CrossRef]

54. Ministry for the Environment (MfE). Coastal Hazards and Climate Change: Guidance for Local Government; Bell, R.G., Lawrence, J., Allan, S., Blackett, P., Stephens, S.A., Eds.; New Zealand Ministry for the Environment Publication: Wellington, New Zealand, under review.

(C) 2017 by the authors. Licensee MDPI, Basel, Switzerland. This article is an open access article distributed under the terms and conditions of the Creative Commons Attribution (CC BY) license (http:/ / creativecommons.org/licenses/by/4.0/). 